\title{
Dependence of the single-scattering properties of small ice crystals on idealized shape models
}

\author{
J. Um and G. M. McFarquhar \\ Department of Atmospheric Sciences, University of Illinois at Urbana-Champaign, Urbana, Illinois, USA
}

Received: 19 October 2010 - Published in Atmos. Chem. Phys. Discuss.: 16 November 2010

Revised: 24 March 2011 - Accepted: 26 March 2011 - Published: 4 April 2011

\begin{abstract}
The projections of small ice crystals (with maximum dimension $<50 \mu \mathrm{m}$ ) appear quasi-circular when imaged by probes on aircraft flying through cloud. Therefore, idealized models constructed to calculate their singlescattering properties have included quasi-spherical models such as Chebyshev particles, Gaussian random spheres, and droxtals. Recently, an ice analogue grown from sodium fluorosilicate solution on a glass substrate, with several columns emanating from a common center of mass, was shown to be quasi-circular when imaged by state-of-the-art cloud probes. In this study, a new idealized model, called the budding Bucky ball (3B) that resembles the shape of the small ice analogue is developed. The corresponding single-scattering properties (scattering phase function $P_{11}$ and asymmetry parameter $g$ ) are computed by a ray-tracing code. Compared with previously used models, 3B scatters less light in the forward and more light in the lateral and backward directions. The Chebyshev particles and Gaussian random spheres show smooth and featureless $P_{11}$, whereas droxtals and 3Bs, which have a faceted structure, show several peaks in $P_{11}$ associated with angles of minimum deviation. Overall, the difference in the forward (lateral; backward) scattering between models are up to $22 \%$ (994\%; 132\%), 20\% (510\%; 101\%), and $16 \%(146 \% ; 156 \%)$ for small ice crystals with respective area ratios of $0.85,0.77$, and 0.69 . The $g$ for different models varies by up to $25 \%, 23 \%$, and $19 \%$ for particles with area ratios of $0.85,0.77$, and 0.69 , respectively. Because the single-scattering properties of small ice crystals depend both on the choice of the idealized model and the area ratios used to characterize the small ice crystals, higher resolution observations of small ice crystals or direct observations of their single-scattering properties are required.
\end{abstract}

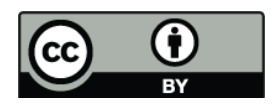

Correspondence to: $\mathrm{J}$. Um (junum@atmos.uiuc.edu)

\section{Introduction}

Because cirrus located in the upper troposphere and lower stratosphere occur at very cold temperatures $\left(<-30^{\circ} \mathrm{C}\right)$, they are mainly composed of ice crystals. Cirrus spatial coverage (Wylie et al., 1994), temporal frequency, microphysical (McFarquhar and Heymsfield, 1997) and scattering properties (Hartmann et al., 1992; Zhang et al., 1999; McFarquhar et al., 2000) have large impacts on how cirrus affects radiation. Despite the importance of cirrus, its representation in small and large-scale models has large uncertainties mainly due to the wide variety of shapes and sizes of non-spherical ice crystals. Thus, its role in modulating the Earth-radiation balance has not been well established (Ramanathan et al., 1983; Liou, 1986; Baum et al., 2000).

A conventional method (McFarquhar et al., 2000) for representing the scattering properties of cirrus in numerical models is to combine measured microphysical properties (e.g., size and habit distributions) of cirrus from field campaigns and pre-calculated single-scattering libraries (e.g., scattering phase function $P_{11}$, asymmetry parameter $g$, and single-scattering albedo) of different shapes and sizes of ice crystals. This method of combining microphysical and single-scattering libraries is also used to develop satellitebased algorithms for retrieving cloud properties (Nasiri et al., 2002; Baum et al., 2007). These parameterization schemes and retrieval algorithms depend heavily on the assumed size and shape distributions, single-scattering libraries of ice crystals, and randomization of idealized ice crystals (Baran and Labonnote, 2007; Baran, 2009; Um and McFarquhar 2009).

To calculate the single-scattering properties of different shapes of ice crystals, idealized models representing the shapes of real ice crystals are needed. Such models have been developed based on images of ice crystals obtained by probes installed on aircraft flying through clouds. In addition to the calculation of single-scattering properties of pristine ice crystal shapes such as hexagonal columns and

Published by Copernicus Publications on behalf of the European Geosciences Union. 


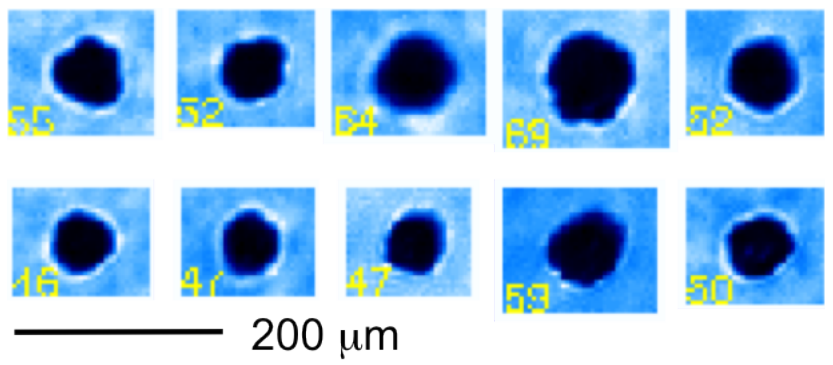

Fig. 1. Example small ice crystals imaged by the CPI during TWPICE. The $200 \mu \mathrm{m}$ scale bar embedded left bottom corner. Maximum dimension is indicated within each image.

plates (e.g., Takano and Liou, 1989; Macke et al., 1996) and bullet rosettes (e.g., Iaquinta et al., 1995), recent studies have extended the calculations to more complex shapes such as aggregates of columns (Yang and Liou, 1998; Baran and Labonnote, 2007), bullet rosettes (Um and McFarquhar, 2007) and plates (Um and McFarquhar, 2009) and to longer wavelengths (Baran, 2005; Yang et al., 2005). Although some earlier studies used images from optical array probes, which have 15 to $25 \mu \mathrm{m}$ resolution, to develop the idealized models, more recent studies have used higher resolution $(2.3 \mu \mathrm{m})$ images from a Cloud Particle Imager (CPI).

Ice crystals with a maximum dimension $D<125 \mu \mathrm{m}$ cannot be well measured by conventional optical array probes because the limited number of photodiodes shadowed prohibits a precise depiction of their shape. Further, a small and poorly defined depth of field limits the ability to determine the small crystal concentrations (e.g., Baumgardner and Korolev, 1997), and the degree to which the shattering of large ice crystals on the tips of such probes artificially amplifies the concentrations of these crystals is unknown (Korolev et al., 2011). Thus, other probes such as the CPI, the Desert Research Institute (DRI) replicator (Arnott et al., 1994) and the Video Ice Particle Sampler (VIPS, McFarquhar and Heymsfield, 1996) have been used to characterize the shape of small ice crystals. Such observations have also indicated that small ice crystals have a quasi-circular appearance in two dimensions. Thus, it has been assumed that small ice crystals are quasi-spherical.

Corresponding idealized models used to describe the shape of small ice crystals have included spheres (McFarquhar et al., 1999), Chebyshev particles obtained by continuous deformations to a sphere using Chebyshev polynominals (McFarquhar et al., 2002), droxtals (Yang et al., 2003), and the Gaussian random sphere geometry (Nousiainen and McFarquhar, 2004). Figure 1 shows typical shapes of ice crystals with $D \sim 50 \mu \mathrm{m}$ imaged by the CPI during the Tropical Warm Pool International Cloud Experiment (TWP-ICE). Currently used idealized models to represent the shape of small ice crystals are shown in Fig. 2. More recently, it has been shown that crystalline particles of sodium fluorosilicate a)

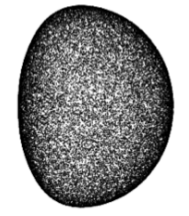

b)

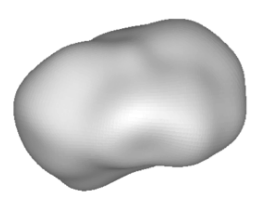

c)

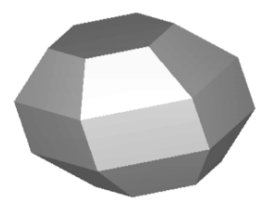

Fig. 2. Idealized models representing shapes of small ice crystals; (a) Chebyshev particle (Mugnai and Wiscombe, 1980); (b) Gaussian random sphere (Nousiainen and McFarquhar, 2004); and (c) droxtal (Yang et al., 2003).

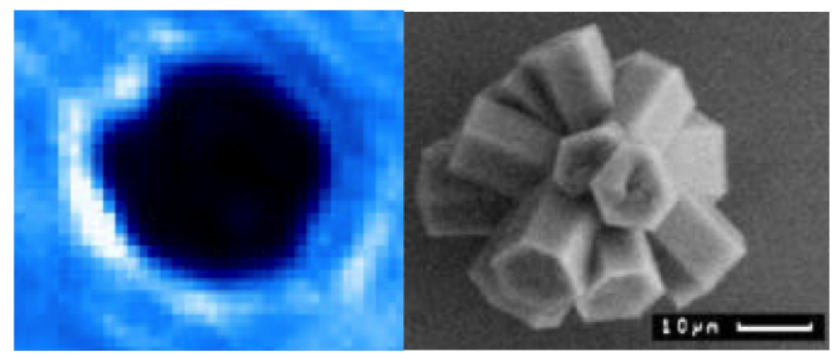

Fig. 3. A small ice analogue $(D=48 \mu \mathrm{m})$ imaged by a CPI (left) and by a scanning electron microscope (right) with $10 \mu \mathrm{m}$ scale bar. Adapted from Ulanowski et al. (2004).

$\mathrm{Na}_{2} \mathrm{SiF}_{6}(D=48 \mu \mathrm{m})$, grown from solution on glass substrates, appear quasi-circular when imaged by a CPI (Fig. 3, Ulanowski et al., 2004). Unlike droxtals, Gaussian random spheres, or Chebyshev particles, these crystalline particles, henceforth called ice analogues, show a complex structure of several columns originating from a common center of mass when imaged by a scanning electron microscope with a resolution as low as 1 to $20 \mathrm{~nm}$. In fact, the crystals of sodium fluorosilicate show morphologies similar to those of large ice crystals (e.g., columns, plates, and bullet rosettes). Highresolution microscopic images of small ice crystals grown in a laboratory have also revealed that 5 to $10 \mu \mathrm{m}$ crystals have facets and that ice crystals larger than $10 \mu \mathrm{m}$ are budding rosettes (Bailey and Hallett, 2009); Other laboratory studies are not appropriate for identifying the shapes of small ice crystals because of limits in the resolution of the camera used (Bailey and Hallett, 2002) or because they only investigated the evolution of crystals larger than $100 \mu \mathrm{m}$ (Bacon et al., 2003). Because the refractive index of ice and sodium fluorosilicate are very close, similar single-scattering properties, such as halos, are generated when lights interacts with them (Ulanowski et al., 2003; Ulanowski et al., 2006).

There is a significant discrepancy in the shapes of the different idealized models (McFarquhar et al., 2002; Yang et al., 2003; Nousiainen and McFarquhar, 2004) that have been used to describe small ice crystals and the small ice analogues. Since the single-scattering properties of ice crystals depend heavily on shape, it is necessary to determine 
appropriate models for small ice crystals and their corresponding single-scattering properties.

It is difficult to identify the detailed shapes of small ice crystals using state-of-the-art cloud probes because the probe resolutions are insufficient to resolve the fine structure of the crystals. In addition, there are few studies on the growth mechanisms for small ice crystals. Field et al. (2006) and McFarquhar et al. $(2007,2011)$ have recently suggested that the shattering of large ice crystals on the inlets or shrouds of some probes may artificially generate small ice crystals that are in turn measured. Thus, caution must be applied to verify that the small ice crystal images represent naturally occurring crystals rather than remnants of shattered large ice crystals.

In this study, a new idealized model of small ice crystals that resembles the ice analogues is developed and the corresponding single-scattering properties are calculated at a solar wavelength of $\lambda=0.55 \mu \mathrm{m}$. Those single-scattering properties are then compared with those of other models previously used to characterize small ice crystals. In Sect. 2, aircraft observations are used to separate images of naturally occurring small ice crystals from those produced by the shattering of large ice crystals. Current models representing the shapes of small ice crystals are summarized and an idealized geometric model that resembles the shape of small ice analogues is developed in Sect. 3. The geometrical optics method used to calculate the single-scattering properties of small ice crystals is described in Sect. 4. The dependence of the singlescattering properties of small ice crystals on shape, aspect ratio, and area ratio is calculated and compared for all plausible small ice crystal models in Sect. 5. The importance and new findings of this study are summarized in Sect. 6 .

\section{Observed shapes of small ice crystals}

Field et al. (2003) showed that ice crystal concentrations measured by a Forward Scattering Spectrometer Probe can be overcounted by a factor of between 2 and 5 . McFarquhar et al. (2007) compared the number concentrations of ice crystals with $D<50 \mu \mathrm{m}$ in tropical cirrus measured by a Cloud and Aerosol Spectrometer (CAS) and a Cloud Droplet Probe (CDP) during TWP-ICE. In ice clouds, the CAS, which has a protruding shroud and inlet, measured much higher concentrations than the CDP, which has its tips farther from the sample volume. The CAS/CDP number concentration ratio was strongly correlated with the concentration of particles with $D>100 \mu \mathrm{m}$ measured by a Cloud Imaging Probe, suggesting that the shattering or bouncing of large ice crystals on the CAS inlet or protruding airflow shroud may have caused the difference.

The CPI, whose images form the basis of many idealized models of small ice crystals, also has protruding components on which large ice crystals may shatter. Thus, it is necessary to estimate the degree to which shattering of large ice crystals on the CPI might be contaminating images of naturally oc- curring small ice crystals. It is likely that the degree of contamination depends heavily on aircraft parameters such as true air speed, pitch, roll, and angle of attack and microphysical parameters such as ice crystal concentration, ice crystal habit, and cirrus mass content. Thus, careful assessment of CPI images acquired in each field campaign, and even in separate flights and components of flights, is required. For this study, data acquired during TWP-ICE are used to estimate the impact of shattering on the crystals imaged by the CPI in tropical cirrus.

The CPI acquires images of ice crystals on a CCD array when a high-power imaging laser is triggered by the detection of a particle in the field of view by two lower-powered lasers shining on photodiode detectors. There can be one or more particles in the field of view recorded on the CCD. In this study, it is hypothesized that when multiple particles are recorded on the same CCD frame, they most likely represent multiple particles generated by the shattering of a large particle. On the other hand, a single particle most likely represents a naturally occurring ice crystal. Among the 180905 particles imaged by the CPI on 3 days during TWP-ICE (27 and 29 January, 2 February 2006), 178102 (98.451\%) particles were the only particles in the frame, while 2596 $(1.435 \%), 186(0.102 \%), 16(0.009 \%)$, and $5(0.003 \%)$ occurred in frames with $2,3,4$, and 5 particles, respectively. This suggests that the shattering of ice crystals on the CPI during TWP-ICE was not frequent so that the quasi-circular small ice crystals in Fig. 1 likely correspond to naturally occurring ice crystals. Other instruments such as the VIPS (McFarquhar and Heymsfield, 1996) have also imaged quasicircular small ice crystals, providing more evidence that not all measurements of small ice crystals are instrument artifacts.

\section{Idealized models representing shapes of small ice crystals}

\subsection{Overview}

Bailey and Hallett (2009) showed that ice crystals grown in the DRI fall tower were faceted or had emerging arms at sizes of $5-10 \mu \mathrm{m}$ at temperatures of around $-42{ }^{\circ} \mathrm{C}$. Small ice crystals larger than $10 \mu \mathrm{m}$ were also faceted and some of them had budding arms when imaged by the DRI highresolution cloud scope. In a qualitative sense, the small ice analogue of Ulanowski et al. (2004) depicted in Fig. 3 is consistent with such crystals in that it has one center of mass from which columns emanate. Figure 2 shows models that have been previously used to represent the shapes of small ice crystals, including Chebyshev particles, Gaussian random spheres, and droxtals. These models do not have the arm structures shown in the small ice analogue and in the small ice crystals grown in the DRI fall tower. At first glance, the existing models appear closer (than the small ice analogues) 
to the quasi-spheres seen in the in-situ measurements (e.g., Fig. 1). But, the small ice analogues also appeared quasicircular when imaged by a CPI (Fig. 3) and hence are also consistent with the in-situ measurements. The CPI is unable to distinguish between such different small crystal shapes because of insufficient resolution and diffraction. Therefore, a new idealized model to represent the shape of the small ice analogues and calculations of the corresponding singlescattering properties are required to determine the sensitivity of the scattering properties to the representation of shape.

In this section, the different methods used to describe the shapes of small ice crystals are explained. A new model that resembles the shapes of small ice analogues is first developed. Thereafter idealized models for small ice crystals with $D=50 \mu \mathrm{m}$ are generated using each of the 4 methods (i.e., Chebyshev particles, Gaussian random spheres, droxtals, and the new model). Because variations in scattering properties can be dominated by differences in particle cross-sectional areas, the models of the small ice crystals were generated so that the cross-sectional area is the same for all the different methods. For each method, 3 different ice crystal models with area ratios of $0.85,0.77$, and 0.69 were generated, where area ratio is defined as the average cross-sectional area of the particle divided by that of circumscribed circle with diameter given by the crystal maximum dimension (McFarquhar and Heymsfield, 1996), $D=50 \mu \mathrm{m}$. The highest area ratio of 0.85 was selected to match the maximum area ratio of droxtals, while the lowest area ratio of 0.69 corresponds to the lowest area ratio of quasi-circular ice crystals with $D<100 \mu \mathrm{m}$ observed by McFarquhar et al. (2002).

\subsection{Chebyshev particle}

Mugnai and Wiscombe (1980) and others have investigated the description of scattering caused by rotationally symmetric scatterers by means of Chebyshev particles (Fig. 2a), which are obtained by continuously deforming a sphere by means of Chebyshev polynomials. McFarquhar et al. (2002) used the tenth-order Chebyshev polynomials of Chuang and Beard (1990) that most closely matched the observed areas of ice crystals imaged in tropical cirrus to describe the shapes of small ice crystals. Thereafter, they calculated their singlescattering properties using the ray tracing method of Macke and Grossklaus (1998).

The geometry of a Chebyshev particle in a spherical coordinate system is represented by the 10th order cosine expansion

$r(\theta, \phi)=r_{\mathrm{o}}\left[1+\sum_{n=0}^{10} c_{\mathrm{n}} \cos (n \theta)\right]$,

where $r_{\mathrm{O}}$ is the radius of the unperturbed sphere and the $c_{\mathrm{n}}$ are the shape coefficients. Chuang and Beard (1990) calculated $c_{\mathrm{n}}$ to describe the shapes of raindrops with $1.0<D<9.0 \mathrm{~mm}$. Macke and Grossklaus (1998) and Nousiainen and Muinonen (1999) then calculated the single- a)

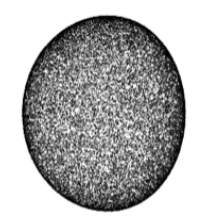

b)

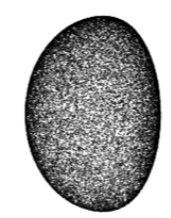

c)

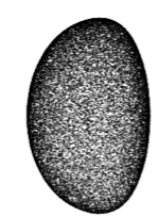

Fig. 4. Chebyshev particles $(D=50 \mu \mathrm{m})$ with varying area ratios of (a) 0.85 , (b) 0.77, and (c) 0.69 . a)

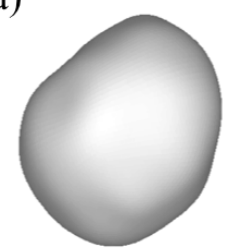

b)

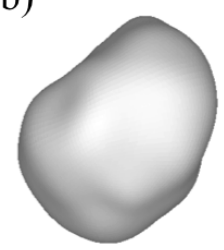

c)

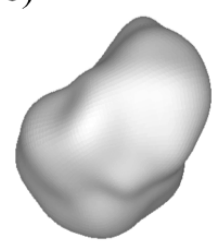

Fig. 5. Gaussian random spheres $(D=50 \mu \mathrm{m})$ with (a) $\sigma=0.069$, (b) $\sigma=0.110$, and (c) $\sigma=0.179$. The corresponding area ratios are (a) 0.85 , (b) 0.77 , and (c) 0.69 .

scattering properties of raindrops using the Chebyshev particles with $c_{\mathrm{n}}$ from Chuang and Beard (1990). McFarquhar et al. (2002) also applied this technique to calculate the singlescattering properties of ice crystals with $D<100 \mu \mathrm{m}$. In this paper, $c_{\mathrm{n}}$ from Chuang and Beard (1990) were used to generate the Chebyshev particles with area ratios of $0.85,0.77$, and 0.69 shown in Fig. 4, where an appropriate scaling factor was applied to $r_{\mathrm{o}}$ so that the maximum dimension is $50 \mu \mathrm{m}$.

\subsection{Gaussian random sphere}

The Gaussian random sphere depicted in Fig. $2 b$ was generated using a statistical shape model that computes the statistical properties of particle shapes, rather than the shapes of individual particles (Muinonen et al., 1996). This model has been used to describe shapes of asteroids (Muinonen and Lagerros, 1998), desert dust particles (Nousiainen et al., 2003), and the shapes of small ice crystals imaged by a CPI in mid-latitude cirrus (Nousiainen and McFarquhar, 2004). Nousiainen and McFarquhar (2004) also calculated the corresponding single-scattering properties of the ice crystals at $\lambda=0.55 \mu \mathrm{m}$ using ray optics.

The shape of a Gaussian random sphere is solely described by a covariance function of radius (Nousiainen and McFarquhar, 2004). In this study, three different shapes of Gaussian random sphere were constructed by varying the relative standard deviation of radius, $\sigma$, used to represent the shapes of small ice crystals. Figure 5 shows the geometric shapes of Gaussian random spheres of $D=50 \mu \mathrm{m}$ with $\sigma=0.069$, 0.110 , and 0.179 that correspond to an area ratio of 0.85 , 0.77 , and 0.69 , respectively. As $\sigma$ increases, a Gaussian random sphere becomes more non-spherical. More details of 
a)

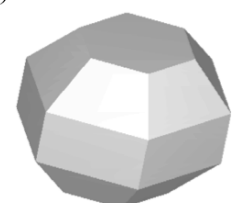

b)

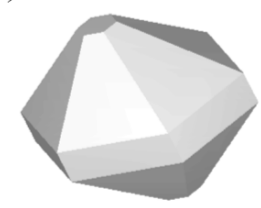

c)

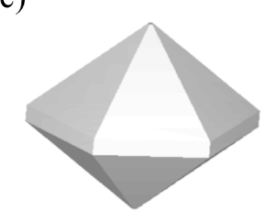

Fig. 6. Droxtals with (a) $\theta_{1}=32.35^{\circ}$ and $\theta_{2}=71.81^{\circ}$, (b) $\theta_{1}=$ $10.00^{\circ}$ and $\theta_{2}=80.00^{\circ}$, and (c) $\theta_{1}=1.5^{\circ}$ and $\theta_{2}=85.0^{\circ}$. The $D$ for each droxtal is $50 \mu \mathrm{m}$ and the corresponding area ratios are (a) 0.85 , (b) 0.77 , and (c) 0.69 .

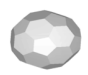

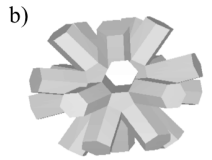
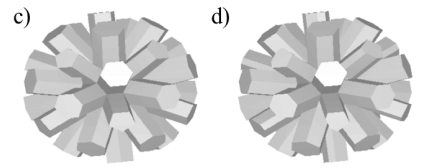

Fig. 7. From left to right: (a) a core of 3B, (b) 3B with 20 regular hexagonal columns, (c) 3B with 20 regular hexagonal and 12 pentagonal columns, and (d) 3B with 20 regular and 12 irregular hexagonal columns.

the Gaussian random sphere are explained in Nousiainen and McFarquhar (2004).

\subsection{Droxtal}

Thuman and Robinson (1954) observed particles with the characteristics of both droplets and crystals in Alaskan ice fogs and named them droxtals. Ohtake (1970) also measured droxtals in ice fogs and developed a schematic drawing of them. Thereafter Yang et al. (2003) proposed an idealized model of a droxtal (see Fig. 2c) and calculated the corresponding single-scattering properties using the finitedifference time domain method (Yang et al., 2003) and geometric optics (Zhang et al., 2004) at solar and infrared $\lambda$.

A droxtal has 20 faces and all the vertices of the droxtal fall on the circumscribing sphere when the droxtal has maximum sphericity (Yang et al., 2003). The geometry of a droxtal is configured with two angles $\left(\theta_{1}\right.$ and $\left.\theta_{2}\right)$ and with a radius of the circumscribing sphere. The detailed geometrical configuration of a droxtal was shown in Yang et al. (2003) and Zhang et al. (2004). The maximum area ratio that the droxtal can make is slightly above 0.85 . In this study, three different shapes of droxtals with $D=50 \mu \mathrm{m}$ were generated (Fig. 6) by varying $\theta_{1}$ and $\theta_{2}$. The area ratio of 0.85 was achieved using $\theta_{1}=32.35^{\circ}$ and $\theta_{2}=71.81^{\circ}$. The combinations, $\theta_{1}=10.00^{\circ}$ and $\theta_{2}=80.00^{\circ}$ and $\theta_{1}=1.5^{\circ}$ and $\theta_{2}=85.00^{\circ}$, generated droxtals with area ratios of 0.77 and 0.69 , respectively. The droxtal with $\theta_{1}=32.35^{\circ}$ (Fig. 6a) is closest to a spherical particle, with the other two droxtals becoming less spherical as $\theta_{1}$ decreases. The singlescattering properties of the droxtals with $\theta_{1}=32.5^{\circ}$ (Fig. 6a) and $\theta_{1}=1.5^{\circ}$ (Fig. 6c) were shown in Zhang et al. (2004).

a)

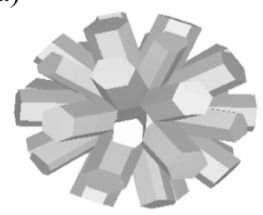

b)

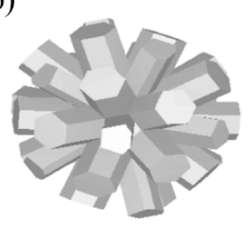

c)

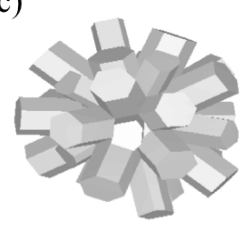

Fig. 8. Examples of $3 \mathrm{Bs}$ with $D=50 \mu \mathrm{m}$ and 20 regular and $12 \mathrm{ir}-$ regular hexagonal columns whose length varies. The corresponding area ratios are (a) 0.85 , (b) 0.77 , and (c) 0.69 .

\subsection{Budding Bucky ball (3B)}

A new model for small ice crystals (henceforth called a budding Bucky ball, 3B) is proposed here. It has a core whose structure is the same as that of carbon 60 fullerene, namely like a soccer ball with 12 pentagonal and 20 hexagonal planes. From these planes, hexagonal or pentagonal columns extend vertically. Figure 7 shows a core and a possible geometrical shape of $3 \mathrm{~B}$. The structure of $3 \mathrm{~B}$ is configured with a radius of core $\left(r_{3 \mathrm{~B}}\right)$, and length $(L)$ and width $(W)$ of the hexagonal or pentagonal columns. A maximum dimension $D$ of a $3 \mathrm{~B}$ is defined as $D=2\left(r_{3 \mathrm{~B}}+L\right)$. Therefore, for a given size of $3 \mathrm{~B}$ (i.e., fixed $D$ ), $L$ determines $r_{3 \mathrm{~B}}$, and vice versa. Since $L$ and $W$ are related through an aspect ratio $(L / W)$, once the desired $D$ and aspect ratio are chosen, $r_{3 \mathrm{~B}}$ is automatically determined. In this paper, $3 \mathrm{Bs}$ with 20 regular and 12 irregular hexagonal columns (Fig. 7d) are used to represent the shapes of small ice crystals, consistent with the small ice analogue in Fig. 3 that has both regular and irregular hexagonal columns. Such irregular or imperfect hexagonal columns have been seen in both nature and in the laboratory (Bacon and Swanson, 2000) and used in scattering calculations (Hess and Wiegner, 1994). The single-scattering properties of other plausible geometrical shapes of 3B (i.e., Fig. 7a, b, and c) are also calculated and shown in Sect. 4.

For a given size of $3 \mathrm{~B}$ (i.e., $D=50 \mu \mathrm{m}$ ), its configuration depends on the aspect ratio of the component column. There are no studies on the aspect ratio of columns on ice analogues. In this study, the aspect ratio derived by Mitchell and Arnott (1994) for columns, $W=0.700 L^{1.00}, L<100 \mu \mathrm{m}$, is used and hence the aspect ratio is 1.43 . The lengths of the emanating columns were adjusted so that the $3 \mathrm{Bs}$ with the same area ratios as the other small crystal models were generated, but the lengths of the two columns emanating in the opposite direction were not changed so that $D=50 \mu \mathrm{m}$. Thus, the area ratio and $D$ of the $3 \mathrm{~B}$ can be matched to the projected area and $D$ of the in-situ measured ice crystals.

Geometries of three 3Bs are shown in Fig. 8. Each 3B has a different average length of the column. The $3 \mathrm{~B}$ with an average $L$ of $13.24 \mu \mathrm{m}$ has an area ratio of 0.85 (Fig. 8a) whereas 3Bs with average $L$ of $11.72 \mu \mathrm{m}$ (Fig. 8b) and $9.95 \mu \mathrm{m}$ (Fig. 8c) have area ratios of 0.77 and 0.69 , respectively. 


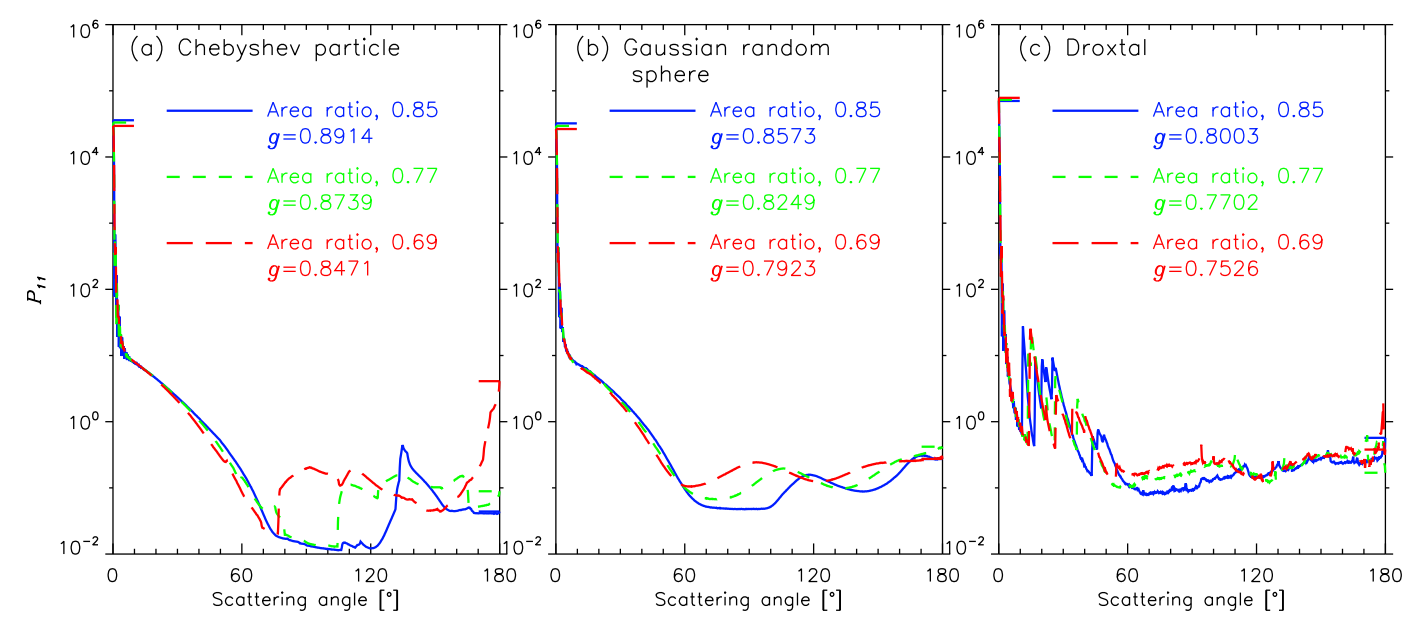

Fig. 9. Scattering phase function $\left(P_{11}\right)$ and asymmetry parameter $(g)$ for (a) Chebyshev particles, (b) Gaussian random spheres, and (c) droxtals with varying area ratio. The direct forward and backward peaks are indicated by bars. The shapes of Chebyshev particles, Gaussian random sphere, and droxtals are shown in Figs. 4, 5, and 6, respectively.

\section{Ray-tracing model}

The parallel version of a geometric ray-tracing code (Um and McFarquhar, 2009), originally developed by Macke et al. (1996), was used to calculate the single-scattering properties of all small ice crystals models except those of Chebyshev particles. To calculate the single-scattering properties of Chebyshev particles, the geometric ray-tracing code of Macke and Grossklaus (1998) was used. For Gaussian random spheres, the Gaussian random sphere geometry was used to generate idealized shape models and then corresponding single-scattering properties were calculated by the parallel version of the geometric ray-tracing code.

Two of the most interesting single-scattering properties for satellite and climate studies are the scattering phase function $P_{11}$ and asymmetry parameter $g$. The $P_{11}$ is normalized to unity, $\frac{1}{4 \pi} \int_{4 \pi} P_{11} d \Omega=1$, and $g$ is defined as $g=$ $\frac{1}{4 \pi} \int_{4 \pi} P_{11} \cos \theta d \Omega$, where $\Omega$ and $\theta$ is the solid angle and scattering angle, respectively. In these codes, the energy and polarization properties of light are defined by the Stokes vector $(I, Q, U, V)$. Reflection and refraction procedures are repeated until the remaining energy of the Stokes vectors of internally reflected rays falls below $10^{-6}$ of the incident energy or until the rays leave the ice crystal. Because small ice crystals do not have preferred orientations in the atmosphere, random orientations are assumed. For each ice crystal used in this study, 240000 random orientations, 2400 rays per orientation, and a scattering angle resolution of $0.25^{\circ}$ are used. These random orientations and rays per orientation are enough numbers to achieve robust singlescattering properties. All numerical computations were carried out for $\lambda=0.55 \mu \mathrm{m}$, for which the refractive index of ice is $1.311+i 2.289 \times 10^{-9}$ (Warren and Brandt, 2008). Since the imaginary part of the refractive index is almost zero, the single-scattering albedo for all simulations are approximately 1 . This ray-tracing code can be used for size parameter $(\pi D / \lambda)$ larger than 65 . In this study, for all ice crystals and the chosen $\lambda$, the size parameters are larger than 285 and hence fall in the geometric optics regime.

\section{Results}

\subsection{Single-scattering properties of previously used models}

The scattering phase function $P_{11}$ and asymmetry parameter $g$ of Chebyshev particles with varying area ratios are shown in Fig. 9a. As the area ratio decreases, Chebyshev particles become more non-spherical (Fig. 4) and the single-scattering properties are affected. The Chebyshev particle with an area ratio of 0.85 shows the scattering characteristics of a sphere with a peak at $134.5^{\circ}$, the angle of minimum deviation or rainbow angle. This angle is a bit smaller than the primary rainbow angle of $138.5^{\circ}$ at $\lambda=0.55 \mu \mathrm{m}$ due to the deformation of the Chebyshev particle from a sphere. As the Chebyshev particle becomes more non-spherical, the primary rainbow angle disappears and the integrated energy in the lateral $\left(60^{\circ}\right.$ to $\left.120^{\circ}\right)$ and backward $\left(120^{\circ}\right.$ to $\left.180^{\circ}\right)$ directions increase, while the integrated energy in the forward $\left(0^{\circ}\right.$ to $60^{\circ}$ ) direction decreases. As a result, $g$ decreases with area ratio with the $g$ of the Chebyshev particle with area ratio 0.77 (0.69) being $2.0 \%(5.23 \%)$ smaller than that with area ratio 0.85 .

Figure $9 \mathrm{~b}$ shows $P_{11}$ and $g$ of Gaussian random spheres with varying $\sigma$, and hence area ratio. There are no sharp peaks in $P_{11}$, which are commonly seen for other nonspherical particles. As the area ratio decreases, the integrated 
energy in the lateral and backward directions increases, while the forward scattering decreases. For example, when the area ratio decreases from 0.85 to $0.77(0.69)$, the forward, lateral, and backward scattering change by $-3.28 \%$ $(-47.45 \%),+66.39 \%(+141.14 \%)$, and $+17.64 \%(+43.33 \%)$, respectively. This decrease in forward scattering and increase in lateral and backward scattering leads to a decrease in $g$. The $g$ for the Gaussian random sphere with area ratio of 0.77 $(0.66)$ differs by $-3.92 \%(-8.20 \%)$ from that for an area ratio of 0.85 .

The shapes of droxtals differ from those of Chebyshev particles and Gaussian random spheres. Droxtals have facets, whereas Chebyshev particles and Gaussian random spheres have smooth surfaces, which lead to relatively smooth and featureless $P_{11}$. The $P_{11}$ for droxtals are characterized by several peaks as shown in Fig. 9c, the peaks being inherent features of faceted particles. The most pronounced peak for droxtals with area ratio of 0.85 is found at $10.50^{\circ}$, while it is at $15.25^{\circ}$ and $14.75^{\circ}$ for droxtals with area ratios of 0.77 and 0.69 , respectively. These peaks are angles of minimum deviation associated with ray refraction through two faces of a particle. Other peaks shown also result from minimum deviations. Droxtals have relatively higher direct forward scattering than that of Chebyshev particles and Gaussian random spheres as shown in Fig. 9 because the several pairs of parallel faces on droxtals allow the direct forward scattering.

As the area ratio decreases, the forward scattering decreases and the lateral and backward scattering increase for droxtals. The decrease in the area of the parallel faces associated with the decreasing area ratio causes the decrease in the direct forward scattering. The energy scattered in the forward, lateral, and backward direction for the droxtal with area ratio of $0.77(0.69)$ differs by $-3.62 \%(-6.19 \%)$, $+46.64 \%(+77.37 \%)$, and $+6.71 \%(+10.60 \%)$ from those of the droxtal with area ratio of 0.85 , respectively. As shown for Chebyshev particles and Gaussian random spheres, this leads to a $3.92 \%$ and $6.34 \%$ decrease in $g$ for the droxtal with area ratio of 0.77 and 0.69 , respectively, compared with that of the droxtal with area ratio of 0.85 . In summary, there are decreases in forward scattering and increases in lateral and backward scattering, and hence decreases in $g$, for Chebyshev particles, Gaussian random spheres, and droxtals with decreasing area ratio. Such trends were previously seen by Um and McFarquhar (2007, 2009) and Baran (2009) who noted lower $g$ as the shape of aggregates particles became more complex.

\subsection{Single-scattering properties of $3 B$}

Before examining how the single-scattering properties of 3Bs depend on area ratio, the single-scattering properties of possible configurations of the 3B shown in Fig. 7 are calculated. Figure 10 shows $P_{11}$ and $g$ of a core and possible geometrical shapes of 3B. The core (Fig. 7a), which has an area ratio of 0.94 and hence is quite close to spherical in shape,

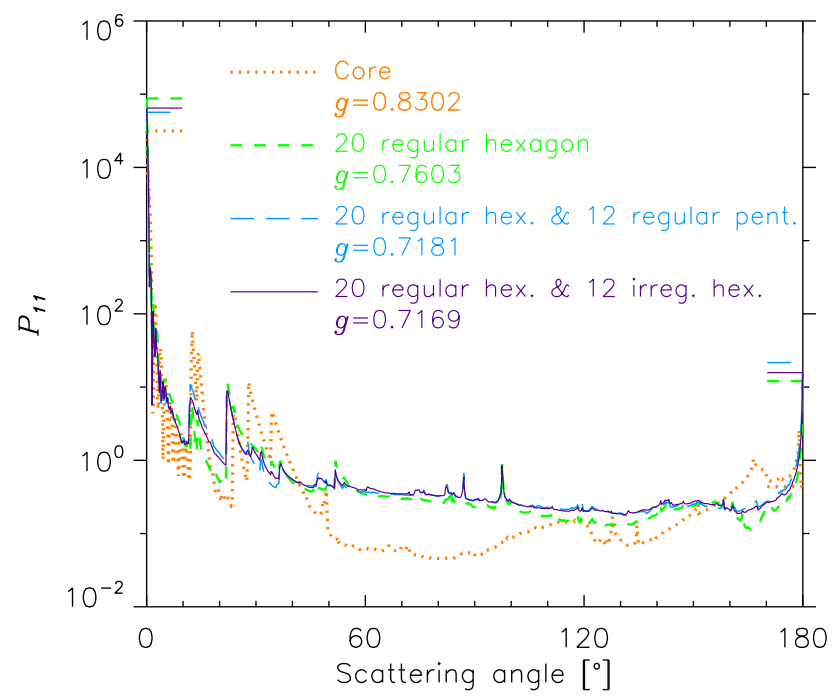

Fig. 10. $P_{11}$ and $g$ for the $3 \mathrm{~B}$ core (yellow), 3B with 20 regular hexagonal columns (green), 3B with 20 regular and 12 regular pentagonal columns (blue), and 3B with 20 regular hexagonal and 12 irregular hexagonal columns (purple). The direct forward and backward peaks are indicated by bars. The shape of each 3B is shown in Fig. 7.

has $D=23.22 \mu \mathrm{m}$. The other configurations with emanating columns have $L$ of $13.39 \mu \mathrm{m}$ and an aspect ratio of 1.43 (Mitchell and Arnott, 1994). The most distinct difference between the $P_{11}$ of the core and that of the other 3B configurations is the lower amounts of lateral scattering from the core. The lateral scattering of the core is $217.70 \%, 283.58 \%$, and $285.27 \%$ less than that of the 3B with 20 regular hexagonal columns (Fig. 7b), with 20 regular hexagonal and 12 regular pentagonal columns (Fig. 7c), and with 20 regular hexagonal and 12 irregular hexagonal columns (Fig. 7d), respectively. This low lateral scattering is also seen for the Chebyshev particles in particular, but also to some degree for the Gaussian random sphere, and droxtal with area ratio of 0.85. Low lateral scattering is a distinct feature of the single-scattering properties of spheres. For the models of 3B with the arm structure, multiple reflections between columns lead to increases in the lateral scattering. The backward scattering of the core differs by $-0.06 \%,+23.77 \%$, and $+25.21 \%$ from that of 3Bs with the arm structures. The multiple reflections caused by the arm structure on the 3B also decreases the forward scattering compared to that of the core. For example, the forward scattering of core is $+10.37 \%,+15.42 \%$, and $+15.60 \%$ greater than that of $3 \mathrm{~B}$ with 20 regular hexagonal columns, with 20 regular hexagonal and 12 regular pentagonal columns, and with 20 regular hexagonal and 12 irregular hexagonal columns, respectively. The 3B with 20 regular hexagonal columns has the highest direct forward scattering because its higher numbers of parallel faces give more direct forward scattering. Due to the decrease in the forward 


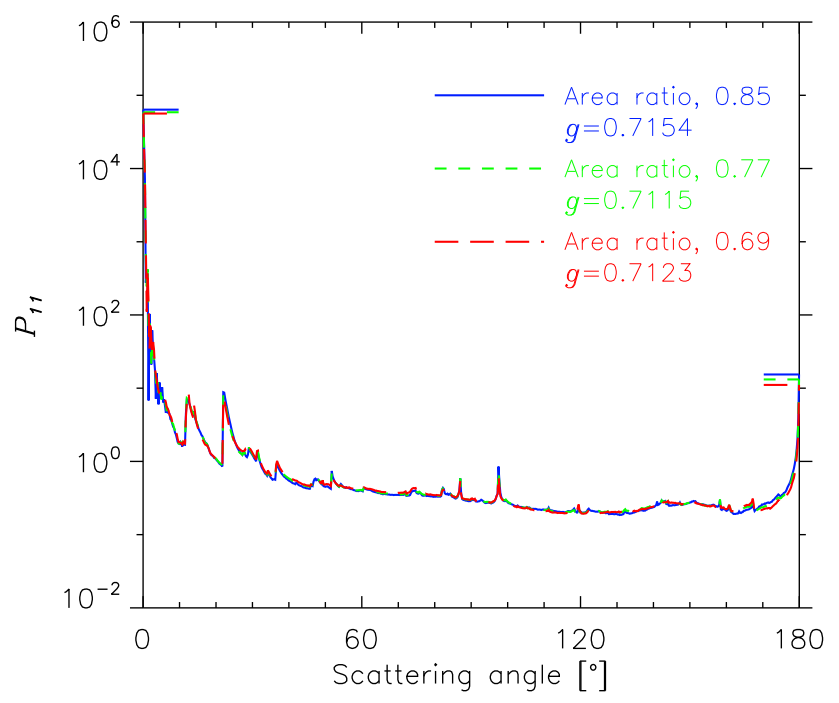

Fig. 11. $P_{11}$ and $g$ for the $3 \mathrm{Bs}$ with varying area ratio. The direct forward and backward peaks are indicated by bars. The shape of each $3 \mathrm{~B}$ is shown in Fig. 8.

scattering and the increase in the lateral and backward scattering, the $g$ of 3Bs with arm structures is lower than that of the $3 \mathrm{~B}$ core by up to $15.79 \%$.

Figure 11 shows $P_{11}$ and $g$ for the 3Bs with aspect ratio of 1.43 for area ratios of $0.85,0.77$, and 0.69 . For changes in area ratio, the $g$ varies by only up to $0.55 \%$, and the forward, lateral, and backward scattering differ by only up to $0.47 \%, 1.75 \%$, and $2.16 \%$, respectively. Compared with results from other small crystal models, these variations in $P_{11}$ and $g$ are small and not significant from the standpoint of how well $g$ must be known for global climate modeling or remote sensing studies. This lack of sensitivity occurs because the method for generating the $3 \mathrm{~B}$ with varying area ratios differs from the methods by which the other shapes are generated. For the 3Bs, the lengths of columns were changed to generate crystals with varying area ratios so that the essential shape of the 3B was not varied; the shapes of other models were somewhat changed to make the crystals with different area ratios.

Another way to generate $3 \mathrm{Bs}$ with different area ratios is to vary the column aspect ratio. Six additional $3 \mathrm{Bs}$, with aspect ratios of 1.0 and 1.7, were generated with the lengths of the columns set so that the area ratio were $0.85,0.77$, and 0.69 . For changes in area ratio for $3 \mathrm{Bs}$ with aspect ratio of 1.0 (1.7), the difference in the integrated energy in the forward, lateral, and backward direction is up to $1.13 \%$ (1.54\%), $0.53 \%$ (4.28\%), and $14.67 \%$ (11.38\%). The $g$ can vary by up to $2.48 \%$ and $2.22 \%$ for the aspect ratio of 1.0 and 1.7 , respectively. As the area ratio decreases from 0.85 to 0.69 , the difference in $g$ between 3Bs with different aspect ratios (i.e., 1.0, 1.43, and 1.7) decreases. For example, $g$ varies by up to $4.46 \%, 2.39 \%$, and $0.94 \%$ with aspect ratio for area ratios of $0.85,0.77$, and 0.69 , respectively. The sensitivity of $g$ to changes in aspect ratio decreases with area ratio because the more compact shape of smaller area ratio crystals produces increased multiple scattering between columns that overwhelms the influence of aspect ratio on the scattering properties. Overall, for all 3Bs examined, $g$ for an area ratio of 0.77 (0.69) can differ by at most 3.60\% (2.88\%) compared to that of a $3 \mathrm{~B}$ with area ratio of 0.85 . Thus, compared with the difference in $g$ of Chebyshev particles (up to 5.23\%), Gaussian random spheres (up to $8.20 \%$ ), and droxtals (up to $6.34 \%$ ) with varying area ratio, variations in $g$ for $3 \mathrm{~B}$ are relatively small.

\subsection{A comparison of single-scattering properties of small ice crystal models}

Figure 12 shows $P_{11}$ and $g$ for different idealized models representing the shapes of small ice crystals as a function of area ratio. The 3B and droxtal show several sharp peaks in $P_{11}$, especially in the forward scattering direction, while the Chebyshev particle and Gaussian random sphere have smooth and featureless $P_{11}$. Because the former have facets, several minimum deviation angles occur and produce pronounced peaks in $P_{11}$. Further, parallel faces on the $3 \mathrm{Bs}$ and droxtals lead to higher direct forward scattering than that for Chebyshev particles and Gaussian random spheres. The Chebyshev particles show the lowest lateral and backward scattering regardless of the area ratio due to the relatively simple shapes. For example, the integrated energy in the lateral (backward) direction for a Chebyshev particle with area ratio of $0.85,0.77$, and 0.69 is $993.79 \%$ (131.70\%), $509.80 \%(101.26 \%)$, and $141.47 \%(147.17 \%)$ less than that for a $3 \mathrm{~B}$ with area ratio of $0.85,0.77$, and 0.69 , respectively. Multiple reflections between columns are effective in the $3 \mathrm{Bs}$ so that the lateral and backward scattering is larger than those for other crystal models. The Chebyshev particles have higher integrated energy in the forward scattering direction than $3 \mathrm{Bs}$, with the difference being $21.56 \%, 20.15 \%$, and $16.12 \%$ for an area ratio of $0.85,0.77$, and 0.69 , respectively. Large differences in directional scattering also exist between the previously used models (i.e., Chebyshev particles, Gaussian random spheres, and droxtals). The forward (lateral and backward) scattering of previously used models differs by up to $8.41 \%$ (325.94\% and $119.70 \%)$ for particles with area ratios of 0.85 and by up to $10.54 \%$ (243.65\% and $99.35 \%)$ and $9.45 \%(67.31 \%$ and $156.11 \%)$ for area ratios of 0.77 and 0.69 , respectively. The Gaussian random sphere and droxtal reveal 5.16\% (66.20\% and 67.37\%), 5.50\% (46.47\% and $51.82 \%$ ), and $3.93 \%$ (22.25\% and $29.15 \%$ ) differences in the forward (lateral and backward) direction for area ratios of $0.85,0.77$, and 0.69 , respectively. Table 1 summarizes the maximum and minimum differences in the integrated energy in the forward, lateral, and backward direction between idealized models for a given area ratio. 
Table 1. Maximum and minimum difference in the forward, lateral, and backward scattering between a Chebyshev particle (CH), a Gaussian random sphere (GS), a droxtal (DX), and a budding Bucky ball (3B) for a given area ratio of small ice crystal. For a given area ratio and directional scattering, the maximum (Max) and minimum (Min) difference (\%) are listed together with the names of the idealized models.

\begin{tabular}{l|ll|ll|ll}
\hline \multirow{2}{*}{ Area ratio } & \multirow{2}{*}{ Direction } & \multicolumn{2}{|c|}{ Forward scattering } & \multicolumn{2}{c|}{ Lateral scattering } & \multicolumn{2}{c}{ Backward scattering } \\
\cline { 3 - 8 } & Max & Min & Max & Min & Max & Min \\
\hline \multirow{2}{*}{0.85} & CH \& 3B & CH \& GS & CH \& 3B & GS \& DX & CH \& 3B & CH \& GS \\
0.77 & $21.56 \%$ & $3.0 \%$ & $993.79 \%$ & $39.83 \%$ & $131.70 \%$ & $23.82 \%$ \\
& CH \& 3B & CH \& GS & CH \& 3B & GS \& DX & CH \& 3B & CH \& GS \\
0.69 & $20.15 \%$ & $4.56 \%$ & $509.80 \%$ & $31.73 \%$ & $101.26 \%$ & $23.84 \%$ \\
& CH \& 3B & GS \& DX & CH \& 3B & GS \& DX & CH \& DX & DX \& 3B \\
\hline
\end{tabular}

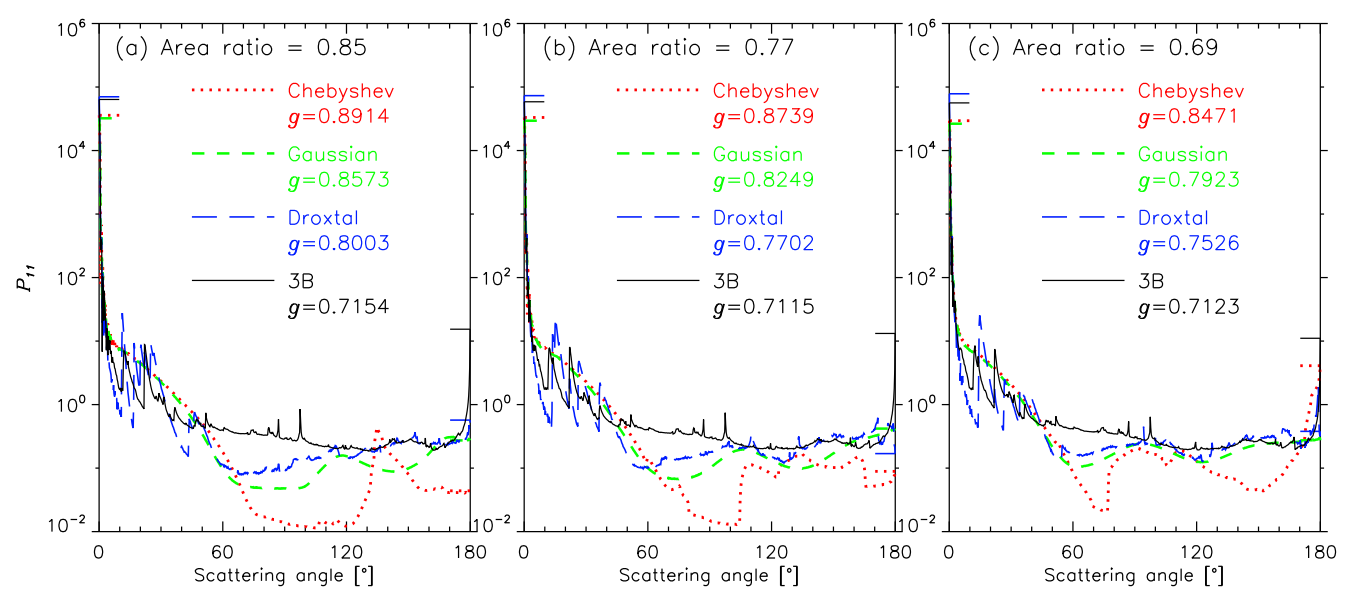

Fig. 12. $P_{11}$ and $g$ for Chebyshev particles, Gaussian random spheres, droxtals, and 3Bs with varying area ratio of 0.85 (a), 0.77 (b), and 0.69 (c). Here, aspect ratio of 1.43 is used for $3 \mathrm{Bs}$. The direct forward and backward peaks are indicated by bars.

The magnitude of the differences in the lateral (up to 993.79\%) and backward (up to $156.11 \%$ ) direction between models that represent shapes of small ice crystals are crucial because most satellite retrievals rely on radiances reflected by clouds in the lateral and backward directions. For example, the maximum range of scattering angles sampled at mid to high latitudes for the Polarization and Directionality of Earth's Reflectances instrument is between $60^{\circ}$ to $180^{\circ}$, and between $120^{\circ}$ and $160^{\circ}$ in the Tropics (Baran and Labonnote, 2007). Although the difference in the forward scattering (3.0 to $21.56 \%$ ) is smaller than that in the lateral and backward directions, the differences are still important because most light is scattered in the forward direction by ice crystals (e.g., 83\% of the light is scattered in the forward direction by droxtals).

Figure 13 shows the degree of linear polarization $\left(-P_{12} / P_{11}\right)$ for different idealized models representing the shapes of small ice crystals as a function of area ratio. Like $P_{11}$, the largest difference in $-P_{12} / P_{11}$ is found between $3 \mathrm{~B}$ and the Chebyshev particle. The $3 \mathrm{Bs}$ show the most featureless $-P_{12} / P_{11}$, whereas Chebyshev particles have large fluctuations that were also shown in raindrop simulations (Macke and Grossklaus, 1998).
Table 2. Maximum and minimum difference in $g$ of idealized models representing shapes of small ice crystals as a function of the area ratio. For a given area ratio of small ice crystal the maximum and minimum difference $(\%)$ between $g$ and the corresponding names of the idealized models are listed. Acronyms for idealized models are the same as in Table 1.

\begin{tabular}{lll}
\hline Area ratio & Maximum difference in $g$ & Minimum difference in $g$ \\
\hline 0.85 & CH \& 3B & CH \& GS \\
& $24.60 \%$ & $3.83 \%$ \\
0.77 & CH \& 3B & CH \& GS \\
& $22.83 \%$ & $5.61 \%$ \\
0.69 & CH \& 3B & GS \& DX \\
& $18.93 \%$ & $5.01 \%$ \\
\hline
\end{tabular}

Table 2 and Fig. 14 summarize variations in $g$ as a function of area ratio for different small crystal models and 3Bs with varying aspect ratio. The $g$ for Chebyshev particles, Gaussian random spheres, and droxtals decrease with decreasing area ratio, whereas the $g$ for $3 \mathrm{Bs}$ depends on the aspect ratio of the component columns. The $g$ for $3 \mathrm{Bs}$ are lower than 


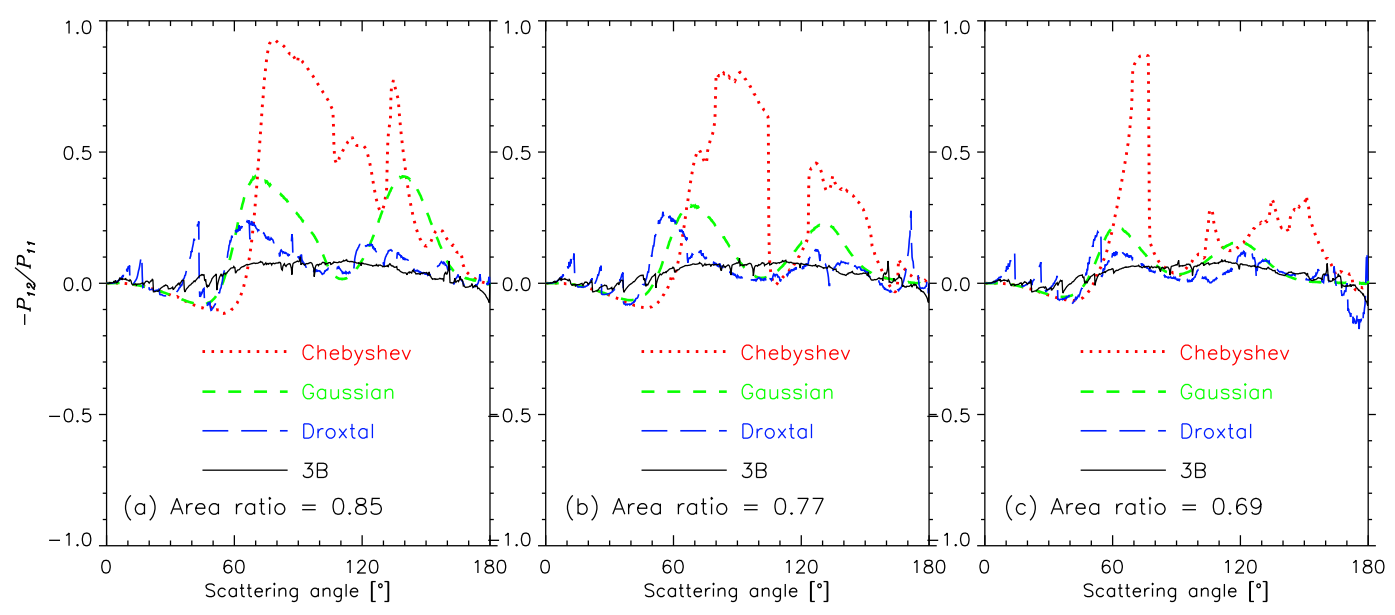

Fig. 13. Degree of linear polarization $\left(-P_{12} / P_{11}\right)$ and for Chebyshev particles, Gaussian random spheres, droxtals, and $3 B$ s with varying area ratio of 0.85 (a), 0.77 (b), and 0.69 (c). Here, aspect ratio of 1.43 is used for 3Bs.

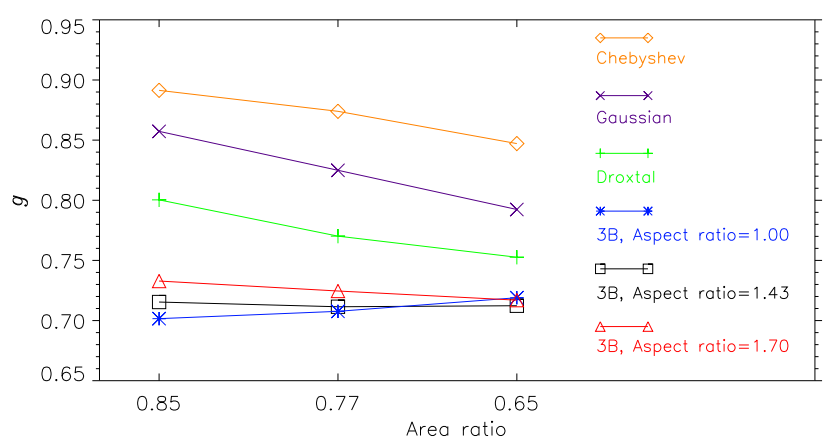

Fig. 14. The $g$ of idealized models representing small ice crystals. In addition to $g$ of 3B with aspect ratio of 1.43 , the $g$ for 3Bs with aspect ratio of 1.0 and 1.7 are also embedded.

those for the other models by up to $24.60 \%$ because the complex shape of the 3Bs allows for more lateral and backward scattering as shown in Fig. 12. The forward scattering from $3 \mathrm{Bs}$ is up to $21.56 \%$ smaller than that from the other models, whereas the integrated energy in the lateral (backward) direction of 3Bs is up to $993.79 \%$ (147.17\%) larger than that from the other models. The maximum difference in $g$ is found between Chebyshev particles and 3Bs regardless of the area ratio, while the minimum difference in $g$ between models is between Chebyshev particles and Gaussian random spheres or between Gaussian random spheres and droxtals depending on the area ratio. The variation in $g$ between previously used models (i.e., Chebyshev particles, Gaussian random spheres, and droxtals) is up to $11.38 \%, 13.47 \%$, and $12.56 \%$ for area ratios of $0.85,0.77$, and 0.69 , respectively.

Overall, the differences in $g$ are up to $24.60 \%$ between the four idealized models representing the same small ice crystals are significant because this is larger than the differences in $g$ between the habits that are used to characterize the larger ice crystals. This variation also exceeds the accuracy of $2 \%$ and $5 \%$ in $g$ for clouds with optical depths of 12 and 2, respectively, required to achieve an accuracy of $\pm 5 \%$ for radiative flux calculation in climates studies (Vogelmann and Ackerman, 1995). Further, numerical simulations have shown that shapes of small ice crystals that predominant in cloud top have strong influences on cloud reflectance calculations (McFarquhar et al., 1999; Yang et al., 2001). Thus, differences in single-scattering properties of small ice crystals due to the choice of different idealized models have climatic and remote-sensing impacts.

\section{Conclusions and discussion}

Images of ice crystals from cloud probes installed on aircraft flying through clouds during TWP-ICE and other field campaigns in diverse geographic regimes have shown that small ice crystals appear quasi-circular. Thus, idealized models previously developed to represent the shapes of small ice crystals, such as Chebyshev particles, Gaussian random spheres, and droxtals, are all quasi-spherical in shape. However, because of insufficient resolution in cloud particle images and diffraction effects associated with state-of-the-art cloud probes, it has been difficult to distinguish the fine structures of small ice crystals and hence to differentiate between the previously used crystal models.

Bailey and Hallett (2009) showed that ice crystals grown in the DRI fall tower were faceted or had emerging arms at sizes of 5-10 $\mu \mathrm{m}$. Some of the ice crystals larger than $10 \mu \mathrm{m}$ were also faceted and had budding arms when imaged by the DRI high-resolution cloud scope. Ulanowski et al. (2004) showed that an ice analogue $(D=48 \mu \mathrm{m})$ grown from sodium fluorosilicate solution on glass substrates, which has a similar crystalline structure to real ice crystals, appeared quasi-circular when imaged by a CPI. This 
ice analogue had a complex structure of several columns originating from a common center of mass, similar to observed small ice crystals in the DRI fall tower. Thus, there is a significant discrepancy between the shapes of the previously used shape models (i.e., Chebyshev particle, Gaussian random sphere, and droxtal) and the shapes of the ice analogue and the small ice crystals grown in the DRI fall tower even though all look similar when imaged by a CPI.

A new idealized model (budding Bucky ball, 3B) that resembles the small ice analogue was developed in this study. The corresponding single-scattering properties of 3B were calculated at $\lambda=0.55 \mu \mathrm{m}$ and compared with those of the other idealized models (i.e., Chebyshev particle, Gaussian random sphere, and droxtal). For each method, 3 different ice crystal models with area ratios of $0.85,0.77$, and 0.69 were generated and the dependence of the single-scattering properties of small ice crystals on the choice of idealized model and area ratio was determined.

The principal findings of this study are summarized as follows:

1. Among the 180905 particles imaged by the CPI on 3 days during TWP-ICE, 178102 (98.451\%) particles were the only particles in a frame, while $2596(1.435 \%)$, $186(0.102 \%), 16(0.009 \%)$, and $5(0.003 \%)$ occurred in frames with 2, 3, 4, and 5 particles, respectively. This suggests that the shattering of ice crystals on the CPI during TWP-ICE was not frequent, and hence the quasicircular small ice crystals in Fig. 1 likely correspond to naturally occurring ice crystals and not shattered artifacts.

2. Arms emanating from the core of a $3 B$ increase the lateral and backward scattering and decrease the forward scattering compared to the core. For example, the forward, lateral, and backward scattering for a 3B with arms differs by up to $-15.60 \%,+285.27 \%$, and $+25.21 \%$ from its core. Due to differences in directional scattering, the $g$ for a 3B with emanating arms is up to $15.79 \%$ smaller than that for its core.

3. Compared with previously used models (i.e., Chebyshev particles, Gaussian random spheres, and droxtals), a 3B scatters less light in the forward (up to $21.56 \%$ ) and more light in the lateral (up to $993.79 \%$ ) and backward (up to $147.17 \%$ ) directions, and hence has smaller $g$ (up to $24.60 \%$ ) regardless of area ratio.

4. The Chebyshev particles and Gaussian random spheres show smooth and featureless $P_{11}$, whereas droxtals and 3Bs, which have a faceted structure, show several sharp peaks in $P_{11}$ associated with angles of minimum deviation.

5. As the area ratio decreases and particles become more non-spherical, the integrated energy in the forward direction decreases and the integrated energy in the lat- eral and backward directions increases for Chebyshev particles, Gaussian random spheres, and droxtals. For example, the forward, lateral, and backward scattering for a Chebyshev particle (Gaussian random sphere and droxtal) increases by $-5.18(-7.45 \%$ and $-6.19 \%)$, $+351.55 \%(+141.14 \%$ and $+77.37 \%)$, and $+23.96 \%$ $(+43.33 \%$ and $+10.60 \%)$ for a decrease in area ratio from 0.85 to 0.69 . This leads to decreases in $g$, with $g$ for a Chebyshev particle (Gaussian random sphere and droxtal) with area ratio of 0.69 being $5.23 \%$ (8.20\% and $6.34 \%$ ) smaller than that for area ratio of 0.85 .

6. The $P_{11}$ and $g$ for $3 \mathrm{~B}$ is less sensitive to the area ratio compared to the previously used models (i.e., Chebyshev particle, Gaussian random sphere, and droxtal). The differences in integrated energy in forward, lateral, and backward direction for 3Bs due to varying the area ratios are only up to $1.54 \%, 4.28 \%$, and $14.67 \%$ with $g$ varying by only up to $2.48 \%$.

7. For a given area ratio, there are large differences in $P_{11}$ between the idealized models (i.e., Chebyshev particle, Gaussian random sphere, droxtal, and 3B). Further, the forward (lateral and backward) scattering for different idealized models varies by up to $21.56 \%$ (993.79\% and $131.70 \%), 20.15 \%$ (509.80\% and $101.26 \%$ ), and $16.12 \%$ (146.47\% and $156.11 \%$ ) for area ratios of 0.85 , 0.77 , and 0.69 , respectively. Even without considering the new 3B model introduced here, the differences between previously used models (i.e., Chebyshev particles, Gaussian random spheres, and droxtals) are still up to $8.41 \%$ (325.94\% and $119.70 \%), 10.54 \%$ (243.65\% and $99.35 \%)$, and $9.45 \%(67.31 \%$ and $156.11 \%)$ in the forward (lateral and backward) scattering for area ratios of $0.85,0.77$, and 0.69 , respectively.

8. The $g$ for different models varies by up to $24.60 \%$, $22.83 \%$, and $18.93 \%$ for area ratios of $0.85,0.77$, and 0.69 , respectively. Even without considering $3 \mathrm{~B}$, the differences between Chebyshev particles, Gaussian random spheres, and droxtals are up to $11.38 \%, 13.47 \%$, and $12.56 \%$.

In summary, the single-scattering properties of small ice crystals depend heavily on the choice of idealized model and area ratio. Because current state-of-the-art cloud probes cannot distinguish between these different models for small crystal shapes, different cloud probes may be needed. This might include probes that provide higher resolution images or that make observations of the scattered light by particles. The Small Ice Detector mark 2 (SID-2, Cotton et al., 2010), which measures the angular distribution of scattered light rather than imaging particles, might provide such information. However, since this probe matches measured angular distribution of scattered light to pre-calculated scattering libraries, it also requires idealized models to calculate corresponding single-scattering properties. Studies on the growth 
mechanisms for small ice crystals are also needed to understand how their shapes depend on atmospheric parameters (e.g., temperature, pressure, and humidity) and on formation mechanisms (heterogeneous versus homogeneous freezing), and how they evolve with time. A subsequent study will also examine how the choice of small crystal models and area ratio affects contributions of small ice crystals on the bulk scattering properties of observed distributions of ice crystals with varying shapes and sizes.

Acknowledgements. This research was supported by the Office of Science (BER), United States Department of Energy under grant numbers DE-FG02-02ER63337, DE-FG02-07ER64378, DE-FG02-09ER64770, and DE-SC0001279 and in part by the National Science Foundation through TeraGrid resources provided by National Institute for Computational Sciences under grant number TG-ATM100017. Data were obtained from the Atmospheric Radiation Measurement program archive, sponsored by the DOE, Office of Science, Office of Biological and Environmental Research Environmental Science Division. The assistance of M. Freer, R. McCoy, T. Tooman, W. Bolton, K. Black, and P. Lawson in the collection of the data during TWP-ICE was appreciated. We thank P. May, J. Mather, and C. Jakob for their efforts in leading TWP-ICE. We thank A. Macke for the original ray-tracing code, K. Muinonen and T. Nousiainen for the Gaussian random sphere code, and D. Wojtowicz for allocating computing power.

Edited by: D. Knopf

\section{References}

Arnott, W. P., Dong, Y. Y., Hallett, J., and Poellot, M. R.: Role of small ice crystals in radiative properties of cirrus: A case study, FIRE II, November 22, 1991, J. Geophys. Res., 99, 1371-1381, 1994.

Bacon, N. J. and Swanson, B. D.: Laboratory measurements of light scattering by single levitated ice crystals, J. Atmos. Sci., 57, 2094-2104, 2000.

Bacon, N. J., Baker, M. B., and Swanson, B. D.: Initial stages in the morphological evolution of vapour-grown ice crystals: A laboratory investigation, Q. J. Roy. Meteorol. Soc., 129, 1903-1927, 2003.

Bailey, M. P. and Hallett, J.: Nucleation effects on the habit of vapour grown ice crystals from -18 to $-42{ }^{\circ} \mathrm{C}$, Q. J. Roy. Meteorol. Soc., 128, 1461-1483, 2002.

Bailey, M. P. and Hallett, J.: A comprehensive habit diagram for atmospheric ice crystals: Confirmation from the laboratory, AIRS II, and other field studies, J. Atmos. Sci., 66, 2888-2899, 2009.

Baran, A. J.: The dependence of cirrus infrared radiative properties on ice crystal geometry and shape of the size-distribution function, Q. J. Roy. Meteorol. Soc., 131, 1129-1142, 2005.

Baran, A. J.: A review of the light scattering properties of cirrus, J. Quant. Spectrosc. Rad., 110, 1239-1260, 2009.

Baran, A. J. and Labonnote, L. C.: A self-consistent scattering model for cirrus. I: The solar region, Q. J. Roy. Meteorol. Soc., 133, 1899-1912, 2007.

Baum, B. A., Kratz, D. P., Yang, P., Ou, S. C., Hu, Y. X., Soulen, P. F., and Tsay, S.-C.: Remote sensing of cloud properties using
MODIS airborne simulator imagery during SUCCESS 1. Data and models, J. Geophys. Res., 105, 11767-11780, 2000.

Baum, B. A., Yang, P., Nasiri, S., Heidinger, A. K., Heymsfield, A., and Li, J.: Bulk scattering properties for the remote sensing of ice clouds. Part III: High-resolution spectral models from 100 to $3250 \mathrm{~cm}^{-1}$, J. Appl. Meteorol. Climatol., 46, 423-434, 2007.

Baumgardner, D. and Korolev, A.: Airspeed corrections for optical array probe sample volumes, J. Atmos. Ocean. Technol., 14, 1224-1229, 1997.

Chuang, C. C. and Beard, K. V.: A numerical model for the equilibrium shape of electrified raindrops, J. Atmos. Sci., 47, 13741389, 1990.

Cotton, R., Osborne, S., Ulanowski, Z., Hirst, E., Kaye, P. H., and Greenaway, R. S.: The ability of the Small Ice Detector (SID-2) to characterize cloud particle and aerosol morphologies obtained during flights of the FAAM BAe-146 research aircraft, J. Atmos. Ocean. Technol., 27, 290-303, 2010.

Field, P. R., Wood, R., and Brown, P. R. A.: Ice particle interarrival times measured with a fast FSSP, J. Atmos. Ocean. Technol., 20, 249-261, 2003.

Field, P. R., Heymsfield, A. J., and Bansemer, A.: Shattering and particle interarrival times measured by optical array probes in ice clouds, J. Atmos. Ocean. Technol., 23, 1357-1371, 2006.

Hartmann, D. L., Ockert-Bell, M. E., and Michelsen, M. L.: The effect of cloud type on earth's energy balance: Global analysis, J. Clim., 5, 1281-1304, 1992.

Hess, M. and Wiegner, M.: COP: a data library of optical properties of hexagonal ice crystals, Appl. Optics, 33, 7740-7746, 1994.

Iaquinta, J., Isaka, H., and Personne, P.: Scattering phase function of bullet rosette ice crystals, J. Atmos. Sci., 52, 1401-1413, 1995.

Korolev, A. V., Emery, E. F., Strapp, J. W., Cober, S. G., Isaac, G. A., Wasey, M., and Marcotte, D.: Small ice particles in tropospheric clouds: fact or artifact?, B. Am. Meteorol. Soc., in press, 2011.

Liou, K. N.: Influence of cirrus clouds on weather and climate processes: A global perspective, Mon. Weather Rev., 114, 11671199, 1986.

Macke, A. and Grossklaus, M.: Light scattering by nonspherical raindrops: Implications for lidar remote sensing of rainrates, J. Quant. Spectrosc. Rad., 60, 355-363, 1998.

Macke, A., Mueller, J., and Raschke, E.: Single scattering properties of atmospheric ice crystals, J. Atmos. Sci., 53, 2813-2825, 1996.

McFarquhar, G. M. and Heymsfield, A. J.: Microphysical characteristics of three anvils sampled during the Central Equatorial Pacific Experiment, J. Atmos. Sci., 53, 2401-2423, 1996.

McFarquhar, G. M. and Heymsfield, A. J.: Parameterization of tropical cirrus ice crystal size distributions and implications for radiative transfer: Results from CEPEX, J. Atmos. Sci., 54, 21872200, 1997.

McFarquhar, G. M., Heymsfield, A. J., Macke, A., Iaquinta, J., and Aulenbach, S. M.: Use of observed ice crystal sizes and shapes to calculate mean-scattering properties and multispectral radiances: CEPEX April 4, 1993, case study, J. Geophys. Res., 104, $31763-$ 31779, 1999.

McFarquhar, G. M., Heymsfield, A. J., Spinhirne, J., and Hart, B.: Thin and subvisual tropopause tropical cirrus: Observations and radiative impacts, J. Atmos. Sci., 57, 1841-1853, 2000.

McFarquhar, G. M., Yang, P., Macke, A., and Baran, A. J.: A new 
parameterization of single scattering solar radiative properties for tropical anvils using observed ice crystal size and shape distributions, J. Atmos. Sci., 59, 2458-2478, 2002.

McFarquhar, G. M., Um, J., Freer, M., Baumgardner, D., Kok, G. L., and Mace, G. G.: Importance of small ice crystals to cirrus properties: Observations from the Tropical Warm Pool International Cloud Experiment (TWP-ICE), Geophys. Res. Lett., 34, L13803, doi:10.1029/2007GL029865, 2007.

McFarquhar, G. M., Ghan, S., Verlinde, J., Korolev, A., Strapp, J. W., Schmid, B., Tomlinson, J. M., Wolde, M., Brooks, S. D., Cziczo, D., Dubey, M. K., Fan, J., Flynn, C., Gultepe, I., Hubbe, J., Gilles, M. K., Laskin, A., Lawson, P., Leaitch, W. R., Liu, P., Liu, X., Lubin, D., Mazzoleni, C., Macdonald, A.-M., Moffet, R. C., Morrison, H., Ovchinnikov, M., Shupe, M. D., Turner, D. D., Xie, S., Zelenyuk, A., Bae, K., Freer, M., and Glen, A.: Indirect and semi-direct aerosol campaign, B. Am. Meteorol. Soc., 92, 183-201, 2011.

Mitchell, D. L. and Arnott, W. P.: A model predicting the evolution of ice particle size spectra and radiative properties of cirrus clouds. Part II: Dependence of absorption and extinction on ice crystal morphology, J. Atmos. Sci., 51, 817-832, 1994.

Mugnai, A. and Wiscombe, W. J.: Scattering of radiation by moderately nonspherical particles, J. Atmos. Sci., 37, 1291-1307, 1980.

Muinonen, K. and Lagerros, J. S. V.: Inversion of shape statistics for small solar system bodies, Astron. Astrophys., 333, 753-761, 1998.

Muinonen, K., Nousiainen, T., Fast, P., Lumme, K., and Peltoniemi, J. I.: Light scattering by Gaussian random particles: Ray optics approximation, J. Quant. Spectrosc. Ra., 55, 577-601, 1996.

Nasiri, S. L., Baum, B. A., Heymsfield, A. J., Yang, P., Poellot, M. R., Kratz, D. P., and Hu, Y. X.: The development of midlatitude cirrus models for MODIS using FIRE-I, FIRE-II, and ARM in situ data, J. Appl. Meteorol., 41, 197-217, 2002.

Nousiainen, T. and Muinonen, K.: Light scattering by Gaussian, randomly oscillating raindrops, J. Quant. Spectrosc. Rad., 63, 643-666, 1999.

Nousiainen, T., Muinonen, K., and Raisanen, P.: Scattering of light by large Saharan dust particles in a modified ray optics approximation, J. Geophys. Res., 108(D1), 4025, doi:10.1029/2001JD001277, 2003.

Nousiainen, T. and McFarquhar, G. M.: Light scattering by quasispherical ice crystals, J. Atmos. Sci., 61, 2229-2248, 2004.

Ohtake, T.: Unusual crystal in ice fog, J. Atmos. Sci., 27, 509-511, 1970.

Ramanathan, V., Pitcher, E. J., Malone, R. C., and Blackmon, M. L.: The response of a spectral general circulation model to refinements in radiative processes, J. Atmos. Sci., 40, 605-630, 1983.

Takano, Y. and Liou, K. N.: Solar radiative transfer in cirrus clouds. Part I: Single-scattering and optical properties of hexagonal ice crystals, J. Atmos. Sci., 46, 3-19, 1989.
Thuman, W. C. and Robinson, E.: Studies of Alaskan ice-fog particles, J. Meteor., 11, 151-156, 1954.

Ulanowski, Z., Hesse, E., Kaye, P. H., Baran, A. J., and Chandrasekhar, R.: Scattering of light from atmospheric ice analogues, J. Quant. Spectrosc. Ra., 79, 1091-1102, 2003.

Ulanowski, Z., Connolly, P., Flynn, M., Gallagher, M., Clarke, A. J. M., and Hesse, E.: Using ice crystal analogues to validate cloud ice parameter retrievals from the CPI ice spectrometer data, 14th International Conference on Clouds and Precipitation, Bologna, Italy, 2004.

Ulanowski, Z., Hesse, E., Kaye, P. H., and Baran, A. J.: Light scattering by complex ice-analogue crystals, J. Quant. Spectrosc. Ra., 100, 382-392, 2006.

Um, J. and McFarquhar, G. M.: Single-scattering properties of aggregates of bullet rosettes in cirrus, J. Appl. Meteorol. Climatol., 46, 757-775, 2007.

Um, J. and McFarquhar, G. M.: Single-scattering properties of aggregates of plates, Q. J. Roy. Meteor. Soc., 135, 291-304, 2009.

Vogelmann, A. M. and Ackerman, T. P.: Relating cirrus cloud properties to observed fluxes: A critical assessment, J. Atmos. Sci., 52, 4285-4301, 1995.

Warren, S. G. and Brandt, S. G.: Optical constants of ice from the ultraviolet to the microwave: A revised compilation, J. Geophys Res., 113, D14220, doi:10.1029/2007JD009744, 2008.

Wylie, D. P., Menzel, W. P., Woolf, H. M., and Strabala, K. I.: 4 years of global cirrus cloud statistics using HIRS, J. Clim., 7, 1972-1986, 1994.

Yang, P. and Liou, K. N.: Single-scattering properties of complex ice crystals in terrestrial atmosphere, Contrib. Atmos. Phys., 71, 223-248, 1998.

Yang, P., Gao, B. C., Baum, B. A., Wiscombe, W. J., Hu, Y. X., Nasiri, S. L., Soulen, P. F., Heymsfield, A. J., McFarquhar, G. M., and Miloshevich, L. M.: Sensitivity of cirrus bidirectional reflectance to vertical inhomogeneity of ice crystal habits and size distributions for two Moderate-Resolution Imaging Spectroradiometer (MODIS) bands, J. Geophys. Res., 106, 1726717291, 2001

Yang, P., Baum, B. A., Heymsfield, A. J., Hu, Y. X., Huang, H.-L., Tsay, S.-C., and Ackerman, S.: Single-scattering properties of droxtals, J. Quant. Spectrosc. Rad., 79-80, 1159-1169, 2003.

Yang, P., Wei, H., Huang, H.-L., Baum, B. A., Hu, Y. X., Kattawar, G. W., Mishchenko, M. I., and Fu, Q.: Scattering and absorption property database for nonspherical ice particles in the near- through far-infrared spectral region, Appl. Optics, 44, 5512-5523, 2005.

Zhang, Y., Macke, A., and Albers, F.: Effect of crystal size spectrum and crystal shape on stratiform cirrus radiative forcing, Atmos. Res., 52, 59-75, 1999.

Zhang, Z. B., Yang, P., Kattawar, G. W., Tsay, S.-C., Baum, B. A., Hu, Y. X., Heymsfield, A. J., and Reichardt, J.: Geometricaloptics solution to light scattering by droxtal ice crystals, Appl. Optics, 43, 2490-2499, 2004. 